\title{
Discussion on traffic capacity and speed limit in work zone on highway
}

\author{
N.C. Huang ${ }^{1, a}$, and PING WANG ${ }^{2, b^{*}}$ \\ ${ }^{1}$ Key Laboratory of Road \& Traffic Engineering Ministry of Education of China, Tongji University, \\ Shanghai, China \\ ${ }^{2}$ Key Laboratory of Road \& Traffic Engineering Ministry of Education of China, Tongji University, \\ Shanghai, China \\ ahningc@163.com, ${ }^{\mathrm{b}}$ lilyshwang@tongji.edu.cn \\ * Corresponding author
}

Keywords: Highway, Work zone, Micro-simulation, Traffic capacity, Speed control

Abstract: Highway road conditions are changed largely in the reconstruction compared to normal operation, with traffic capacity falling down due to lane closures, changing lanes frequently caused by merging compulsory, and more accidents resulting from vehicle conflict. Based on VISSIM simulation software, this paper typically studied the most common way of construction, that two-way four-lane, close for single lane, analyzed the effect on the traffic capacity of the work zone in different conditions, and proposed reasonable speed limit option for the security of the work zone.

\section{Introduction}

Along with the rapid growth of highway mileage in our country, highway traffic volume also shows a growing trend. For part of the highway is reconstructed in the first class Highway, which results in the road surface conditions and traffic facilities destroyed in varying degrees. Highway construction and maintenance are becoming more and more frequent, leading to highway traffic jams and accidents. ${ }^{[1]}$ Therefore, research on the traffic organization of highway construction is a pressing issue. Compared with the general highway, the traffic condition of work zone has been changed significantly. Because the number of lanes reduced, it leads to the phenomenon of traffic diverge and traffic merge. These changes cause large impact on driving behavior and traffic flow of the work zone. Study on traffic flow and safety of highway work zone is necessary. ${ }^{[2]}$

Simulation analysis is to estimate the road situation in advance by simulation models, which is inexpensive, efficient and repeatable. This article mainly uses the VISSIM, a micro-simulation tool, to analyze the most common way of construction, half edge construction while opening. Two issues are mainly discussed: the change of traffic capacity brought by lane closures, proposing a reasonable speed limit method for the work zone's safety.

\section{Traffic Characteristics in Work Zone on Highway}

Currently, there are there common modes of highway construction: half edge construction while opening, half edge close while another opening, completely enclosed. This paper mainly discusses the most common construction mode, two-way four-lane close for single lane, which the carriageway lane is occupied, while the overtaking lane is opening. ${ }^{[3]}$ According to the related standard, the work zone can be divided into the following sections: construction notices section, upstream transition section, upstream buffer section, work zone, downstream buffer section, downstream transition section, termination section. Compared with normal road, characteristics of traffic flow on work zone change greatly, leading to the phenomenon of traffic diverge and traffic merge, following, queuing. Especially, for two-way four-lane close for single lane, for the vehicles in the carriageway lane are force sink into overtaking lane, it will result in the redistribution of traffic flow. ${ }^{[4]}$ Simulation model diagram drawn by VISSIM chooses, $2000 \mathrm{~m}$ for construction notices section, $200 \mathrm{~m}$ for upstream transition section, $100 \mathrm{~m}$ for upstream buffer section, $500 \mathrm{~m}$ for work zone, $50 \mathrm{~m}$ for downstream buffer section, $100 \mathrm{~m}$ for downstream transition section, $500 \mathrm{~m}$ for termination section. The proportion of 
large vehicles is $2 \%$ by default. Accordingly, the priority rules and the sign of speed limit should be set. The model diagram is shown in Figure 1.

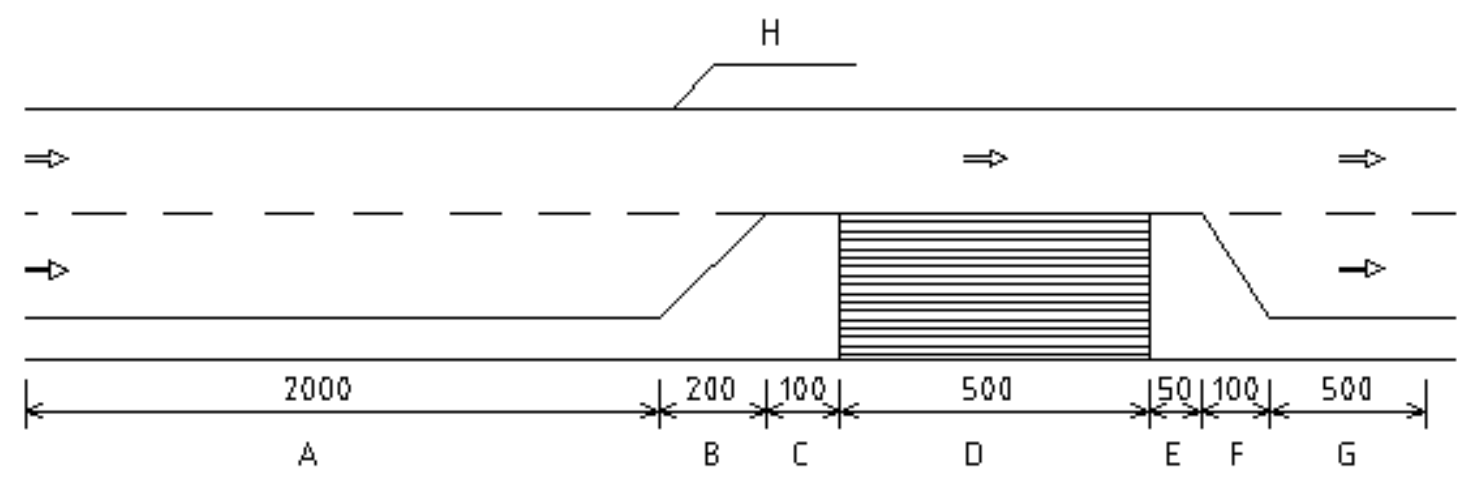

* A: construction notices, B: upstream transition section, C: upstream buffer section, D: work zone, E: downstream buffer section, F: downstream transition section, G: termination section, H: medial divider.

Figure 1. Simulation model of work zone, two-way four-lane, close for single lane.

\section{Simulation of Traffic Capacity}

\section{Traffic Capacity of Work Zone}

In upstream transition section, due to the number of lanes reduced, vehicles must be merged, thus it prone to cause traffic congestion, where usually become traffic bottlenecks. Compared with normal road the traffic capacity of work zone was reduced, in order to maintain the efficient operation of the entire road network, it is necessary to set network diversion measures, according to the traffic capacity of work zone, as well as some scheme about current-limiting. ${ }^{[5]}$ Based on VISSIM simulation methods, setting data collection points, we can get the number of vehicles going through the work zone under different circumstances, by analysis evaluating files.

For typical two-way four-lane, close for single lane, whose the design speed is $120 \mathrm{~km} / \mathrm{h}$, we set $70 \mathrm{~km} / \mathrm{h}$ as speed limit value, and use the Simulation model shown in Figure 1. Then set several data collection points in the work zone. The whole simulation time is $4000 \mathrm{~s}$. The former $400 \mathrm{~s}$ is the time to make traffic flow become stable, and the data between $400 \mathrm{~s}$ to $4000 \mathrm{~s}$ should be collected. At $300 \mathrm{vel} / \mathrm{h}$ intervals gradually increased inputs of the vehicle, by evaluating files it can output the number of vehicles going through the work zone, as shown in Table 1.

Table 1 . The traffic capacity of work zone, when entering vehicles is different.

\begin{tabular}{|c|c|c|c|c|c|c|c|}
\hline vel/h & 600 & 900 & 1200 & 1500 & 1800 & 2100 & 2400 \\
\hline Traffic capacity & 599 & 898 & 1194 & 1496 & 1776 & 1861 & 1859 \\
\hline
\end{tabular}

Obviously, as the increases of arrival traffic, the number of vehicles going through the work zone has been gradually increasing. When the number of enter vehicle reaches $1860 \mathrm{vel} / \mathrm{h}$, the number of vehicles going through the work zone is becoming stable and no longer increase. It's said that road has reached saturated, namely the traffic capacity of road is around $1860 \mathrm{vel} / \mathrm{h}$.

\section{Influence of Large Vehicles' Proportion and Slope on Traffic Capacity}

For the maintenance and construction of highway will create attraction for large vehicle, in the work zone, the proportion of large vehicles is often higher than that in the normal level. Taking into account that a part of highway may have a slight slope, due to the large vehicles often owns the poor maneuverability and climbing ability, slope on its vehicles have a certain impact. So it's necessary to study the influence of models and slope on traffic capacity of the work zone. In this simulation test, the design speed of cars is $120 \mathrm{~km} / \mathrm{h}$, while the design speed of large vehicles is $100 \mathrm{~km} / \mathrm{h}$. We design two sets of variables, one is the proportion of large 
vehicle, the other is the slope of highway. There are 7 different proportions of the large vehicles: $0 \%, 5 \%$, $10 \%, 20 \%, 25 \%, 30 \%$, by modifying the vehicle compositions of VISSIM. $-2 \%, 0 \%, 2 \%$ three kinds of different slopes, as shown in Table 2.

Table 2. The traffic capacity of work zone, when models and slope is different.

\begin{tabular}{|c|c|c|c|c|c|c|c|}
\hline $\mathrm{vel} / \mathrm{h}$ & $0 \%$ & $5 \%$ & $10 \%$ & $15 \%$ & $20 \%$ & $25 \%$ & $30 \%$ \\
\hline$-2 \%$ & 1930 & 1867 & 1792 & 1734 & 1651 & 1623 & 1576 \\
\hline $0 \%$ & 1885 & 1832 & 1743 & 1680 & 1619 & 1578 & 1529 \\
\hline $2 \%$ & 1853 & 1776 & 1691 & 1632 & 1584 & 1538 & 1464 \\
\hline
\end{tabular}

Obviously, with the increase of large vehicles' proportion, the traffic capacity of the work zone is decreasing. At the same time when the vehicles go uphill the traffic capacity is larger, when the vehicles go downhill the traffic capacity is lower. Especially, when the vehicles go uphill, with the increasing of large vehicles' proportion, the traffic capacity decreases more drastically than when the vehicles go downhill. Thus, for the vehicles going uphill, larger vehicles has a greater degree of influence on traffic capacity.

\section{Influence of Length of Upstream Transition Section on Traffic Capacity}

The work zone includes upstream transition section and downstream transition section. When vehicles go through the upstream transition section, they need to change lanes merging into the overtaking lane, due to the lane closures. ${ }^{[6]}$ So the length of the upstream transition section has important impact on the operational efficiency and safety of the work zone.

According to the road traffic signs and markings (G5768-2009), the length of upstream transition section, namely $\mathrm{D}$ in the below, can be computed as formula 1 :

$$
\begin{aligned}
& D=\frac{V^{2} \cdot W}{155}(V \leq 60 \mathrm{~km} / h) \\
& D=\frac{V \cdot W}{1.6}(V>60 \mathrm{~km} / \mathrm{h})
\end{aligned}
$$

In the formula, $\mathrm{W}$ represents the decrement on the width of the road, $\mathrm{V}$ represents the speed limit in the work zone. With the speed limit of $70 \mathrm{~km} / \mathrm{h}$, the length of upstream transition section should be $164.4 \mathrm{~m}$, so the value of upstream transition section in the simulation can be $120 \mathrm{~m}, 140 \mathrm{~m}, 160 \mathrm{~m}, 180 \mathrm{~m}, 200 \mathrm{~m}, 220 \mathrm{~m}$, $240 \mathrm{~m}$. The speed is designed as $120 \mathrm{~km} / \mathrm{h}$. The proportion of large vehicles should be $2 \%$. The rest should be default values. Then the traffic capacity can be simulated by VISSIM, as shown in Table 3.

Table 3. The traffic capacity of work zone, under different length of upstream transition section.

\begin{tabular}{|c|c|c|c|c|c|c|c|}
\hline $\mathrm{vel} / \mathrm{h}$ & $120 \mathrm{~m}$ & $140 \mathrm{~m}$ & $160 \mathrm{~m}$ & $180 \mathrm{~m}$ & $200 \mathrm{~m}$ & $220 \mathrm{~m}$ & $240 \mathrm{~m}$ \\
\hline Traffic capacity & 1747 & 1794 & 1843 & 1870 & 1849 & 1813 & 1762 \\
\hline
\end{tabular}

With the merging length increasing, the traffic capacity increases as well before $180 \mathrm{~m}$, while the capacity falls down after $180 \mathrm{~m}$. It can be concluded that around $180 \mathrm{~m}$ should be the upstream transition section.

\section{Study on Speed Control}

\section{Evaluation} [7]

The paper selects average speed, saturation, traffic density, average traveldelay as evaluation parameters.

Dynamic comprehensive evaluation method is selected, combined with the specificity of traffic organization assessment index. It includes the following steps: 
1. The process of reverse index. In the dynamic comprehensive evaluation method, the reverse index takes advantage as the number goes down. The positive index is opposite. Before comprehensive assessment, reverse index should be transformed into positive index. As for the process of reverse index, the number of traffic density, saturation, traffic delay is smaller the better, while the average speed is just the opposite. The unit of average speed should be converted as $100 \mathrm{~km} / \mathrm{h}$.

2. The dimensionless treatment. The dimension of the four assessment indexes varies, and the number is different sharply. Extreme value method is chosen in the comparison between different dimension numbers. The specific formula 2 is as followed:

$$
\begin{aligned}
& M_{j}=\max _{i}\left\{x_{i j}\right\}, m_{j}=\min _{i}\left\{x_{i j}\right\}, \\
& \text { Then, } x_{i j}^{*}=\frac{x_{i j}-m_{j}}{M_{j}-m_{j}} \text { is no outline, so } x_{i j}^{*} \in[0,1] .
\end{aligned}
$$

In the formula, the maximum value and minimum value of saturation is respectively 1 and 0 . The maximum value and minimum value of average speed is respectively $80 \mathrm{~km} / \mathrm{h}$ and $10 \mathrm{~km} / \mathrm{h}$. The maximum value and minimum value of travel delay is respectively $200 \mathrm{~s} / \mathrm{vel} / \mathrm{km}$ and 0 . The maximum value and minimum value of traffic density is respectively $200 \mathrm{pcu} / \mathrm{km} / \mathrm{ln}$ and 0 .Through extreme value method, inverse evaluation indicators are transformed to a value between 0 and 1 , that is, dimensionless.

3. The calculating of final assessment index .After the process of dimensionless treatment, each index makes summation together, resulting the formula of comprehensive assessment method: $y=\sum_{i=1}^{4} x_{i}^{2}$. It indicates that for the values of dynamic comprehensive evaluation, the smaller the better.

\section{Speed Limit}

Referring to the relevant norms, the speed should limit between $60-80 \mathrm{~km} / \mathrm{h}$, before vehicles come into upstream transition section. ${ }^{[8]}$ If the speed goes down directly from $120 \mathrm{~km} / \mathrm{h}$ to $60 \mathrm{~km} / \mathrm{h}$, mistakes are easily made by drivers, and traffic accidents tend to occur because of the large discreteness of speeds. So, speed limit signs should be set to remind drivers to slow down. Five speed limit options are given in Table 4.

Table 4. Speed limit signs set options.

\begin{tabular}{|c|c|c|c|}
\hline Speed limit $[\mathrm{km} / \mathrm{h}]$ & $\begin{array}{c}\text { The first speed limit } \\
\text { sign }\end{array}$ & $\begin{array}{c}\text { The second speed limit } \\
\text { sign }\end{array}$ & $\begin{array}{c}\text { The third speed limit } \\
\text { sign }\end{array}$ \\
\hline Option one & $60(500 \mathrm{~m})$ & $/$ & $/$ \\
\hline Option two & $70(500 \mathrm{~m})$ & $/$ & $/$ \\
\hline Option three & $90(1200 \mathrm{~m})$ & $60(100 \mathrm{~m})$ & $/$ \\
\hline Option four & $90(1200 \mathrm{~m})$ & $70(100 \mathrm{~m})$ & $60(100 \mathrm{~m})$ \\
\hline Option five & $100(2000 \mathrm{~m})$ & $80(500 \mathrm{~m})$ & $/$ \\
\hline
\end{tabular}

* The numbers in parentheses are the distance between speed limit signs to upstream transition section. 
Table 5. Simulation output values of dynamic comprehensive evaluation.

\begin{tabular}{|l|l|l|l|l|l|}
\hline & Option one & Option two & Option three & Option four & Option five \\
\hline Saturation[v/c] & 0.734 & 0.691 & 0.715 & 0.672 & 0.704 \\
\hline $\begin{array}{l}\text { Average } \\
\text { speed[100h/km] }\end{array}$ & 59.03 & 68.45 & 58.59 & 67.78 & 58.21 \\
\hline Delay[s/vel/km] & 26.01 & 27.04 & 25.52 & 26.48 & 24.87 \\
\hline Density[pcu/km/ ln] & 13.14 & 11.86 & 11.03 & 9.93 & 10.76 \\
\hline $\begin{array}{l}\text { Evaluation index } \\
\text { value }\end{array}$ & 0.5625 & 0.5336 & 0.4995 & 0.4722 & 0.5168 \\
\hline
\end{tabular}

After comparing the function values of various options in Table 5, the priority for the options can be described as followed: option four, option three, option five, option two, option one. It can be concluded that two symbols are preferred than only one in preventing the speed changing too quickly. It may be inconvenient for drivers to brake frequently for option five, and less efficient than two symbols. The final evaluation value of option two with evaluation value of using $70 \mathrm{~km} / \mathrm{h}$ is better than that of option one with evaluation value of using $60 \mathrm{~km} / \mathrm{h}$. So, option four can be the best choice, with two signs in the work zone.

\section{Position of Speed Limit Signs}

For the same speed limit sign, it may produce different results when set in different positions. ${ }^{[9]}$ If the speed limit sign is set in unreasonable position, it may cause negative influence for the safety of the work zone. For the two signs, $90 \mathrm{~km} / \mathrm{h}$ and $70 \mathrm{~km} / \mathrm{h}$, there are several solutions for the position in Table 6 . Then the best option can be selected from simulation analysis.

Table 6. Speed limit signs set options.

\begin{tabular}{|c|c|c|}
\hline $\begin{array}{c}\text { From the transition area } \\
\text { of the upper }\end{array}$ & $\begin{array}{c}\text { position of the } 90 \\
\mathrm{~km} / \mathrm{h} \text { speed limit }\end{array}$ & $\begin{array}{c}\text { position of the } 70 \\
\mathrm{~km} / \mathrm{h} \text { speed limit }\end{array}$ \\
\hline Option one & $2000 \mathrm{~m}$ & $100 \mathrm{~m}$ \\
\hline Option two & $2000 \mathrm{~m}$ & $500 \mathrm{~m}$ \\
\hline Option three & $1200 \mathrm{~m}$ & $100 \mathrm{~m}$ \\
\hline Option four & $1200 \mathrm{~m}$ & $500 \mathrm{~m}$ \\
\hline
\end{tabular}

Table 7. Simulation output values of dynamic comprehensive evaluation.

\begin{tabular}{|c|c|c|c|c|}
\hline & Option one & Option two & Option three & Option four \\
\hline Saturation[v/c] & 0.654 & 0.677 & 0.672 & 0.693 \\
\hline $\begin{array}{c}\text { Average } \\
\text { speed[100h/km] }\end{array}$ & 68.24 & 68.13 & 67.78 & 67.53 \\
\hline Delay[s/vel/km] & 26.03 & 25.14 & 26.48 & 25.21 \\
\hline Density[pcu/km/ln] & 10.07 & 9.71 & 9.93 & 10.21 \\
\hline Evaluation index value & 0.4477 & 0.4771 & 0.4722 & 0.4994 \\
\hline
\end{tabular}

After comparing the function values of various options in Table 7, option 1, option 2 and option 3 work considerably, while option 4 works the worst. The first sign set far from the upstream transition section about $2000 \mathrm{~m}$ is better than that about $1000 \mathrm{~m}$, because drivers have enough time to brake. But when the second speed limit sign set $500 \mathrm{~m}$ far from the upstream transition section, works less effectively, because vehicles may cause traffic jams from slowing down too early. On the contrary, when the second speed limit sign is set 
$100 \mathrm{~m}$ far from the upstream transition section, vehicles can complete the merging process efficiently. Thus it can be concluded that for the work zone, setting the sign with $90 \mathrm{~km} / \mathrm{h}$ and $2000 \mathrm{~m}$ far from the upstream transition section and the other with $60 \mathrm{~km} / \mathrm{h}$ and $100 \mathrm{~m}$ far from the upstream transition section works the best, as shown in Figure 2.

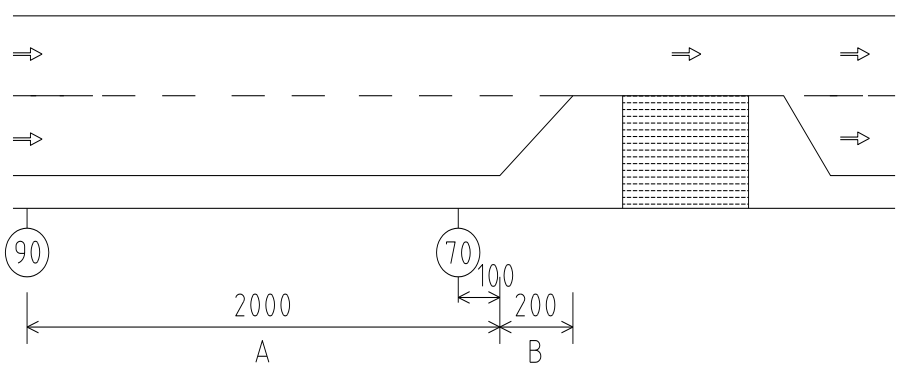

* A: construction notices, B: upstream transition section.

Figure 2. Positions of speed limit signs.

\section{Summary}

The condition of roads and the traffic flow differentiates greatly from the normal section in the process of highway reconstruction. Detailed studies for vehicles on the work zone can be implemented in practice, due to limits on the condition. Based on VISSIM simulation software, this paper typically studied two-way four-lane, close for single lane in the half edge construction while opening, made simulated analysis in the changes of traffic capacity in the work zone, and speed limit options. These conclusions should provide some beneficial information for the traffic organization analysis in the highway reconstruction.

\section{References}

[1] Federal Highway Administration Manual on Uniform Traffic Control Devices for streets and highways (MUTCD) [R] Washington DC: U.S. Department of Transportation, 2003.

[2] GB5768-2009. Road traffic signs and markings. Beijing, China Sta-tistical Publishing House, 2009.

[3] JTG H30-2004. Road traffic signs and markings. Beijing, China Statistical Publishing House, 2004.

[4] Fu, Xinsha. 2012. Freeway rebuilding operation area setting analysis of the influence on traffic capacity, China Journal of Highway 2012, 32(2):264-267.

[5] Wang, Qiang. 2010. Study on speed limitation of highway, Traffic information and safety, 1(28):124-129.

[6] Bi Haifeng. 2011. Highway construction work zone traffic control and simulation study.[D] HITHarbin Institute of Technology: 33-36.

[7] Li Yongyi. 2006. Research on the traffic organization of high-way construction program design and evaluation. [D] Southeast University: 21-24.

[8] Chen, Xiaohong. 2001. Mixed traffic micro-simulation study on characteristics of, China Journal of Highway 12(14):88-91.

[9] Qiu, Dong. 2001. Multi-index synthetic evaluation method of system analysis, Beijing, China statistical Publishing House 12(14):103-112. 